ТАЛЫНЁВ Валерий Егорович - доктор социологических наук, доцент; профессор кафедры социально-гуманитарных, экономических и правовых дисциплин Воронежского института МВД РФ (396947, Воронежская обл., Семилукский p-н, с. Терновое, ул. Рублевская, 5; v.talynyov@уапdex.ru) ХВОИН Николай Николаевич - ведущий специалист отдела мониторинга систем оплаты труда и ведомственного контроля Комитета по труду и занятости населения Санкт-Петербурга (190000, Россия, г. Санкт-Петербург, ул. Галерная, 7; khv-nikolai@yandex.ru)

\title{
К ВОПРОСУ СУЩНОСТНОГО ОПРЕДЕЛЕНИЯ ПОНЯТИЯ «БЕЗДОМНЫЙ»: ИСТОРИЧЕСКИЙ ГЕНЕЗИС
}

\begin{abstract}
Аннотация. В статье рассматриваются методологические подходы к генезису понятия «бездомный», классифицируются подходы к его изучению, а также уточняется сущность понятия «бездомный». На основе социологических исследований применительно к современным условиям развития государственности авторы определяют его содержание и предлагают авторское определение понятия.

Ключевые слова: бездомные, нищие, бродяжничество, приют, социальная помощь
\end{abstract}

И стория человеческой цивилизации показывает, что бездомные, несмотря на властные перипетии, существовали во все времена ее развития. В некоторой степени еще со времен царской России к бездомным относят такую категорию граждан, как крепостные, которые не имели никаких прав, в т.ч. на жилье. Нам представляется, что после отмены в России в 1861 г. крепостного права крестьяне, не сумевшие адаптироваться к новым условиям жизни в обществе, оказались в условиях крайней нищеты и без крыши над головой, что повлекло за собой всплеск бродяжничества.

В сложившейся современной научной практике категория «бездомность» имеет различные толкования. Так, у С.И. Ожегова дано следующее определение понятия «бездомный» - тот, у кого нет своего дома, крова, пристанища, приюта ${ }^{1}$. В англо-русском словаре «бездомность» определяется как «отсутствие какого-либо дома или постоянного места жительства» ${ }^{2}$. В этой ситуации находятся «люди, живущие на улицах, в общежитиях, незаконно занятых жилищах или временном помещении без постоянного права владения» ${ }^{3}$.

В ходе исследования авторами классифицированы следующие подходы к изучению генезиса понятия «бездомный»: 1) исторический подход (выявлены/ определены причины формирования категории бездомных граждан на различных этапах формирования российской государственности); 2) правовой подход (создание приемников-распределителей на всей территории СССР, введение уголовного преследования за занятие бродяжничеством, попрошайничеством либо ведение иного паразитического образа жизни); 3) социально-правовой подход (формирование нормативно-правовой базы, ориентированной на предоставление социальных услуг бездомным); 4) социально-информационный подход (формирование в обществе средствами массовой информации негативных стереотипов о бездомных); 5) социологический подход (проведение

1 Толковый словарь русского языка С.И. Ожегова. Доступ: http://slovarozhegova.ru/word. php?wordid=1294 (проверено 17.03.2018).

2 Англо-русский «Больщой толковый социологический словарь» (под ред. Д. Джери). М. 2001. T. 1. С. 48-49. Доступ: http://www.alleng.ru/d/sociol/soc037.htm (проверено 18.03.2018).

3 Там же. 
социологических исследований бездомных как социальной группы граждан, не имеющих жилья).

В рамках исторического подхода вопросы бездомности были освещены в дореволюционной литературе на рубеже XIX-XX вв. в отечественных исследованиях [Левенстим 1900; Дриль 2002; Сперанский 1897; Максимов 1901; Голосенко 1996]. Следует отметить, что в указанных работах бездомность рассматривалась не как отдельный элемент социального бытия, продукт действия властных структур, а в совокупности изучения вопросов нищенства и бродяжничества, которые изучались достаточно обстоятельно, но, на наш взгляд, несколько однобоко. По отношению к бездомным в то время употреблялось понятие «нищеброд», которое объединяло в себе два определения: «нищий» и «бродяга». Именно эти подходы и характеризовали категорию людей, не имеющих собственного или ведомственного жилья, которые не занимались трудовой деятельностью и вынужденных из-за ряда других причин добывать средства для существования сбором милостыни, различного рода подаяний.

Само по себе слово «тунеядец» возникло еще во времена Российской империи, но не подразумевало какой-либо состав преступления, т.е. социально значимого, опасного, отрицательного контекста понятие «тунеядство» тогда не имело. Просто это явление не одобрялось обществом, и только. В Советском Союзе для обозначения «антиобщественных элементов» вводится новая категория граждан - «тунеядцы», а нищенство и бродяжничество рассматриваются как разновидности тунеядства. В нашей стране, таким образом, история борьбы с таким явлением, как тунеядство, связана в основном с советским периодом развития государственности.

В советский период отдельные исследования по проблемам бездомности целенаправленно не проводились. Позиция власти в отношении бродяг и попрошаек основывалась в основном на мерах «воспитательного и лечебного характера». С точки зрения официальной партийной идеологии бездомных граждан социалистического общества, которых официально именовали попрошайками, бродягами, в Советском Союзе просто быть не могло. С принятием в 1936 г. Конституции СССР трудовая деятельность была объявлена «обязанностью и делом чести» каждого, кто способен к ней. При этом явление бездомности оценивалось как несовместимое с социалистическим образом жизни [Григорьева, Бородкина, Молчанов 2008]; наглядным показателем бездомности являлось попрошайничество. Справедливости ради следует подчеркнуть, что советские граждане уже начали получать в это время от государства жилье на более льготных условиях, чем ранее. Отсюда бедность и нужда уже не являлись главным оправдательным мотивом распространения попрошайничества, как это наблюдалось в первые послевоенные годы, и к проблеме бездомности имели косвенное отношение. Считалось, что такое положение напрямую связано с отношением личности к социальной действительности, а именно ленью, нежеланием заставить себя заниматься трудовой деятельностью.

Во второй половине 50-х гг. XX в. проблема нищенства стала восприниматься в ином социальном контексте. В результате улучшения экономической ситуации в стране, проведения активной жилищной и взвешенной пенсионной реформ, повышения уровня заработной платы стал повышаться уровень жизни населения, отсюда проблема бездомности в области государственной власти отступала на второй план.

Создавшаяся ситуация была учтена при работе над новым уголовным законодательством, в связи с чем авторы статьи выделяют правовой подход к изучению вопросов бродяжничества и попрошайничества, а также рас- 
сматривают возникновение понятия «бомж». В целях повышения уровня эффективности борьбы с тунеядством, с гражданами, которые не пожелали расстаться с бродячим образом жизни и попрошайничеством, а также пресечения и предупреждения преступлений со стороны антиобщественных, паразитических элементов, злостно уклоняющихся от трудовой деятельности и не имеющих определенного местожительства, 23 июля 1951 г. был издан указ Президиума Верховного совета $\mathrm{CCCP}^{1}$. Статистика показывает, что в соответствии с этим указом органами милиции было задержано нищих: во II полугодии 1951 г. - 107766 советских граждан, в 1952 г. - 156 817, а в 1953 г. - 182342 гражданина.

Начало более активной борьбы государства с нищенством и бродяжничеством в советский период приходится на 1950-1960-е гг., что отмечено в ряде работ [Зубкова 2013; Крушанова 2014; Беркутов, Кравченко 2016; Слободкин 1980]. В этот период формируется нормативно-правовая и материальная база, в т.ч. на всей территории СССР создаются приемники-распределители.

Учитывая сложность проблемы, спустя почти 15 лет после окончания Великой Отечественной войны 4 мая 1961 г. Президиум Верховного совета РСФСР принимает указ, направленный на дальнейшее усиление борьбы с «отдельными лицами, которые, являясь трудоспособными, упорно не желают честно трудиться, ведут антиобщественный паразитический образ жизни. Тунеядцами признавались граждане, не имеющие работу более четырех месяцев в году. Женщины, воспитывающие маленьких детей, и студенты были исключением» 2 . По этому указу для тунеядцев предусматривалось наказание - выселение в «специально отведенные местности» на срок от 2 до 5 лет (с конфискацией имущества и принудительным трудом) и др.

В 1961 г. вступает в действие ст. 209 УК РСФСР «Занятие бродяжничеством или попрошайничеством либо ведение иного паразитического образа жизни», которая предусматривала лишение свободы на срок до 2 лет или исправительные работы на срок от 6 месяцев до одного года 3 . Однако главной субъектной мишенью «антипаразитарной» нормативно-правой практики были снова не нищие и бродяги. Именно борьба с таким явлением, как тунеядство, стала частью государственного курса по преодолению общественных «аномалий» и одновременно составной частью кампании по мобилизации трудовых ресурсов по всей стране. В этот период развития страны нормой считалась исключительно работа на государство, а все остальные занятия проходили по разряду отклонений, обозначенных как «уклонение от общественно полезного труда». В этой кампании такая категория, как нищие и прочие девианты, сначала отошла на второй план, а потом и вовсе растворилась в абстрактной категории «лиц, ведущих паразитический образ жизни» [Зубкова 2013].

В Уголовных кодексах союзных республик появились статьи, предусматривающие ужесточение ответственности за «систематическое занятие бродяжничеством и попрошайничеством» (т.е. фактически - за профессиональное нищенство).

\footnotetext{
1 Указ Верховного Совета СССР от 23 июля 1951 г. «О мерах борьбы с антиобщественными, паразитическими элементами». - Справочно-правовая система «Консультант Плюс». Послед. обновление 08.07.2020.

2 Указ Президиума Верховного Совета РСФСР от 04.051961 «Об усилении борьбы с лицами, уклоняющимися от общественно-полезного труда и ведущими антиобщественный паразитический образ жизни» (с изм. и доп., внесенными Указом Президиума ВС РСФСР от 20.09.1965). - Ведомости ВС РСФСР. 1965. N 38, ст. 932.

3 Комментарий к Уголовному кодексу РСФСР 1960 г. С. 355. - Справочно-правовая система «Консультант Плюс». Послед. обновление 08.07.2020.
} 
Бродяжничество в уголовно-правовой трактовке характеризовалось двумя важнейшими признаками: 1) перемещением лица в течение длительного периода из одного населенного пункта в другой либо в пределах одного города и не имеющего определенного места жительства или оставившего его; 2) проживанием на нетрудовые доходы [Слободкин 1980].

Именно в этот период в милицейских протоколах в отношении лиц без определенного места жительства появилась аббревиатура БОМЖ, которая впоследствии перекочевала в СМИ, а затем - и в обиходный русский язык. С той поры в коммуникативной практике аббревиатура БОМЖ стала именем нарицательным, приобрела некий унизительно-презрительный оттенок и используется в обществе не столько для идентификации собственно бездомных, сколько для обозначения любых опустившихся маргиналов, чей облик, образ жизни в той или иной степени схожи с обликом и образом жизни представителей «придонного» слоя бездомных граждан.

На основе проведенных исследований на сегодняшний день в рамках действующего законодательства авторы выделяют социально-правовой подход, который в бо́льшей степени ориентирован на предоставление социальных услуг бездомным гражданам. Однако понятие «бездомный» до сих пор определено лишь фрагментарно и не закреплено должным образом в федеральных законах, в которых, помимо этого, не нашло своего отражения положение дел с нищими, бродягами, попрошайками и др.

С 01.01.2007 г. был введен в действие стандарт, определяющий категории клиентов социальной службы, на основании которого в субъектах России были разработаны региональные стандарты, которые утверждались локальными нормативными правовыми актами как система работы с бездомными гражданами. Таким образом, здесь впервые была определена категория бездомного: «гражданин, не имеющий регистрации по месту жительства в качестве собственника, по договору найма или поднайма, договору аренды или на иных основаниях, предусмотренных законодательством Российской Федерации, или не имеющий возможности проживать по месту регистрации по независящим от него причинам» 1 .

Стоит отметить, что данный стандарт не является обязательным к применению, в связи с чем в учредительных документах (уставах) учреждений социальной помощи (защиты), региональных стандартах по оказанию социальных услуг отсутствует единый подход к определению понятия «бездомный», и нередко можно встретить различные формулировки, определяющие указанную категорию граждан: БОМЖиЗ - гражданин без определенного места жительства и занятий, БОМЖиРЗ - гражданин без определенного места жительства и рода занятий, БОМЖиР - гражданин без определенного места жительства и работы. Данные аббревиатуры, как мы отметили выше, использовались в протоколах советской милиции и были закреплены в учредительных документах приемников-распределителей, которые в дальнейшем были переданы в ведение органов социальной защиты.

Право обращения бездомных в государственные учреждения социального обслуживания населения являлось одним из установленных законом признаков трудного жизненного положения, объективно нарушающего жизнедеятельность индивида, а именно отсутствием определенного места жительства. Этот признак трудной жизненной ситуации был закреплен в федеральном

1 ГОСТ Р 52495-2005. Национальный стандарт Российской Федерации. Социальное обслуживание населения. Термины и определения. М.: Стандартинформ. 2006. 12 с. Справочноправовая система «Консультант Плюс». Послед. обновление 02.03.2020. 
законе от 10.12.1995 г. ${ }^{1}$ При этом обрашение в социальные службы осуществлялось на добровольной основе [Хвоин 2018]. Данная законодательная норма просуществовала до 31 декабря 2014 г.

С 1 января 2015 г. вступил в действие федеральный закон № 442 от 28.12.20132, в связи с чем был подготовлен ряд нормативных правовых актов для последующей их реализации на региональном уровне.

На федеральном уровне понятие «бездомный» так и не было закреплено законодательно. Исключением стали отдельные субъекты нашего государства, которые на нормативно-правовом уровне закрепили понятие бездомного, но, к сожалению, следует подчеркнуть, что это - единичные случаи [Хвоин 2018].

Сегодня, например, закон г. Санкт-Петербурга «О социальном обслуживании населения в Санкт-Петербурге» дает следующее определение бездомного - гражданина без определенного места жительства: «гражданин Российской Федерации, не имеющий регистрации по месту жительства или по месту пребывания в Российской Федерации и не имеющий на территории Российской Федерации жилого помещения (доли в жилом помещении) на праве собственности, жилого помещения по договорам найма (поднайма), социального найма, безвозмездного пользования» ${ }^{3}$. Данная норма увеличивает возможности бездомных на предоставление различных услуг и реализацию конституционных и гражданских прав.

В г. Санкт-Петербурге при предоставлении различных видов услуг, в т.ч. при назначении ежемесячных и ежегодных выплат различным категориям граждан, утверждены 17 административных регламентов, предусматривающих оказание услуг гражданам, не имеющим регистрации в Санкт-Петербурге, но состоящим на социальном учете бездомных в центре учета. Бо́льшая часть административных регламентов отнесена к компетенции Комитета по социальной политике Санкт-Петербурга, а несколько отнесены к ведению Комитета по образованию и Жилищного комитета.

Правозащитник Санкт-Петербургской благотворительной организации «Ночлежка» И.З. Карлинский для определения бездомности предлагал следующие формулировки:

a) состояние (социальное положение) человека, связанное с отсутствием у него прав на конкретное жилое помещение (здание, строение), которое он мог бы использовать для проживания или пребывания и в котором он мог бы зарегистрироваться по месту жительства или по месту пребывания;

б) социальное явление, связанное с отсутствием у людей прав на конкретные жилые помещения (здания, строения), которые они могли бы использовать для проживания или пребывания, и отсутствием у этих людей регистрации по месту жительства или по месту пребывания [Карлинский 2004].

В рамках социально-информационного подхода мы продолжаем изучать понятие «бездомные» и стереотипы, связанные с ними, которые, по мнению авторов, сформированы средствами массовой информации, однобоко преподносящими информацию о бездомных в негативном формате. Укоренившийся

\footnotetext{
1 Федеральный закон РФ от 10.12.1995 № 195-Ф3 «Об основах социального обслуживания населения в Российской Федерации». Доступ: http://www.consultant.ru/document/ cons_doc_LAW_8574/ (проверено 18.05.2021).

2 Федеральный закон от 28.12.2013 № 442-Ф3 «Об основах социального обслуживания граждан в Российской Федерации». Доступ: http://www.consultant.ru/document/cons_doc_ LAW_156558/ (проверено 18.05.2021).

3 О социальном обслуживании населения в Санкт-Петербурге: закон Санкт-Петербурга от 26.12.2014 № 717-135. - Справочно-правовая система «Консультант Плюс». Послед. обновление 07.03.2018.
} 
в обществе стереотип, что бездомные 1) попрошайки и «потрошители» мусорных контейнеров, 2) представляют опасность для общества, 3) сознательно выбирают бездомный образ жизни (личный выбор бездомного), не в полной мере соответствует действительности, что подтверждается результатами исследований [Ринн 2008: 8].

Изучая принципы формирования образа бездомного человека на страницах печатных и электронных изданий «Российской газеты», «Известий», «Аргументов и фактов» в 2013 и 2014 гг., авторы отмечают, что в процессе освещения феномена бездомности в СМИ главной является тенденция демонизации образа бездомного человека, в основе которой лежит стереотипное восприятие. За границами осмысления остаются одни из главных причин появления этого образа, такие как бедность, отсутствие работы, семейные проблемы, низкий уровень жизни граждан и т.д.

Распространен принятый в СМИ подход, что формирование стереотипа понятия «бомж» связано с описанием маргинальной личности, способной на любое преступление или обязательно связанной с криминалом. Дискриминация людей без определенного места жительства в первую очередь проявляется в том, что общественное сознание объединяет всех бездомных в одну социальную группу, присвоив ей некоторый набор негативных характеристик и уничижительные наименования «бомжи», «социальные аутсайдеры», «маргиналы» и др. Таким образом создаются ярлыки, работающие на стигматизацию. Авторы анализируемых текстов не разводят понятия «нищие», «попрошайки», «бездомные», «бродяги», объединяя их в одну группу - «социальное дно», тем самым формируя негативное отношение общества к данной стратификационной группе.

Д. Пазио-Влазловская провела анализ материалов прессы за 2010-2014 гг. на основе шести источников («Российская газета», «Независимая газета», «Комсомольская правда», «Труд», «Московский комсомолец», «Известия»). Она отмечает, что формирование образа бездомного в СМИ носит явно негативный характер, согласно которому бездомный - это член общины, руководствующейся нормами поведения, резко отличающимися от норм поведения, господствующих в «нормальном» обществе. Часто он болен, нередко это алкоголик или преступник, человек глубоко травмированный, который привык к своей жизни и не хочет ее менять. Бездомному нужно помогать выжить (особенно зимой), хотя он не всегда хочет пользоваться предлагаемой ему помощью [Пазио-Влазловская 2015].

С точки зрения социологического подхода категория бездомных граждан исследовалась и продолжает изучаться как отдельная социальная группа граждан, не имеющая жилья и являющаяся разнородной по своему составу, включая в себя практически все слои социально незащищенного населения: пенсионеров, инвалидов, лиц из числа детей-сирот и детей, оставшихся без попечения родителей, семьи с несовершеннолетними детьми, а также граждан трудоспособного возраста. В основном данные исследования проводятся волонтерами благотворительных организаций за счет различных грантов, а также студентами образовательных организаций высшего образования, но их число явно недостаточно.

К примеру, в процессе поиска электронная библиотека диссертаций disserCat выделяет около 40 документов, в содержании которых присутствует ключевое слово «бездомность», из них в 16 документах ключевое слово находится и в названии работ. Не более десятка научных трудов посвящены изучению образа бездомного в русской литературе, зато более 5 работ посвящены учету бездомных животных. 
Нами были выделены диссертационные работы, в названии которых встречаются слова «бездомность», «бездомный», «лица без определенного места жительства», «бомж». Так, в период с 1996 по 2018 г. по проблеме бездомности подготовлено около 15 диссертационных работ на соискание ученой степени кандидата наук. Среди них более 10 работ по социологии, несколько по медицинским и биологическим наукам, культурологии и юриспруденции. Среди крупных исследований можно выделить межрегиональное исследование «Правовые и социальные проблемы бездомности в России», исследование Е. Коваленко и Е. Строковой «Бездомность: есть ли выход» [Социальные и правовые... 2007; Коваленко, Строкова 2010].

Более активное изучение проблемы бездомности в новой России началось в середине 1990-х гг. Одно из первых и крупных исследований социального дна было проведено в 1996 г. Институтом социально-экономических проблем народонаселения РАН под руководством Н.М. Римашевской [Римашевская 2004]. Проведенное исследование позволило выделить четыре группы населения социального дна: 1) нищие, открыто просящие подаяние, 2) бомжи, лишившиеся своего жилья, 3) беспризорные дети, 4) уличные проститутки.

Также стоит отметить исследователей, отдельные работы которых посвящены изучению бездомных [Стивенсон 1996; Алексеева 2003; Соловьева 2001; Коваленко, Строкова 2010; Завьялова, Спиридонова 2000; Осинский, Хабаева, Балдаева 2003].

В юридической науке имеются отдельные работы, посвященные различным аспектам правового положения бездомных в России, однако попытки провести комплексный монографический анализ существующей проблемы с позиций общей теории права до настоящего времени не предпринимались [Халак 2012].

В.В. Волков предпринял попытку создания типологии бездомных, адекватную современной российской действительности, обозначив три типа бездомных граждан: фактически бездомные граждане (уличная бездомность), юридически бездомные граждане (скрытая, латентная бездомность); потенциально бездомные граждане (граждане, находящиеся в группе риска) [Волков 2010].

На наш взгляд, вне поля зрения государственных служб, организаций и исследователей остаются граждане, входящие в состав второго (скрытая, латентная бездомность) и третьего (потенциально бездомные) типов бездомности, поскольку бездомные обращаются за помощью, оказавшись в составе первого типа бездомности (уличная бездомность).

В заключение необходимо отметить уровень статистического аспекта учета бездомности. Так, по данным всесоюзной переписи, бездомные стали учитываться в «домохозяйствах». По результатам переписи в Воронежской обл. в 2002 г. Росстат насчитал 248, а в 2010 г. - уже 296 домохозяйств бездомных. Странно, но волонтеры подсчитывают собак поголовно и решают вопросы об определении бездомных собак в приемники. А что представляет собой домохозяйство бездомных? Сколько членов насчитывается в нем? Ведь домохозяйства бездомных (по мнению Росстата) - это группа лиц или одно лицо без определенного места жительства (не имеющие жилья) ${ }^{1}$. Естественно, адекватный учет числа бездомных, проживающих в таких домохозяйствах, весьма поверхностный. Отсюда и цифры: от 60 тыс. по официальным данным до 3,5-5 млн по утверждениям политиков, региональных СМИ.

1 Приказ Росстата от 04.02.2010 г. № 81 «Об Основных методологических и организационных положениях Всероссийской переписи населения 2010 года» (вместе с «Основными методологическими и организационными положениями...» утв. Росстатом 22.01.2010). 
Авторы отмечают, что все же основной причиной бездомности является кризис «семейных отношений», поскольку многие бездомные имеют родственников, но не поддерживают с ними отношения. Выявлен достаточно высокий процент населения, которые равнодушно и отрицательно относятся к бездомным, в т.ч. и среди работников, осуществляющих работу с бездомными (сотрудники полиции, медицинские и социальные работники). Только небольшая часть населения готова помогать бездомным и участвовать в различных мероприятиях.

Таким образом, генезис содержания понятия «бездомность» имеет длительную историю. Это явление характерно для всего развития человеческой цивилизации, российской государственности и связано с другими социально-политическими, экономическими и другими факторами, в первую очередь с уровнем материального обеспечения, социальными условиями проживания и др.

Исходя из анализа указанных выше понятий, авторы предлагают следующее определение понятия бездомного: это «гражданин без определенного места жительства - гражданин, не имеющий жилого помещения и/или регистрации по месту жительства (месту пребывания), находящийся в состоянии открытой (уличной) или скрытой (латентной) бездомности в силу экономических, правовых, социальных, психологических и других причин».

\section{Список литературы}

Алексеева Л.С. 2003. Бездомные как объект социальной дискредитации. Социс. Социологические исследования. № 9. С. 52-61.

Беркутов А.С., Кравченко Е.В. 2016. Борьба с бродяжничеством в СССР в 1950-е - 1960-е годы. - Философия права. № 2. С. 104-111.

Волков В.В. 2010. Бездомность в современной России: проблема типологии бездомных. - Вестник Нижегородского университета им. Н.И. Лобачевского. № 4. С. 336-370.

Голосенко И.А. 1996. Нищенство как социальная проблема: Из истории дореволюционной социологии бедности. - Социс. Социологические исследования. № 7. С. 27-35.

Григорьева И.А., Бородкина О.И., Молчанов А.А. 2008. Социальная работа с лицами без определенного места жительства: учебное пособие. СПб: Изд-во СПбГУ. 133 с.

Дриль Д.А. 2002. Уголовная социология. Фрагменты работ разных лет. Социология и социальная антропология. № 4. С. 32-39.

Завьялова Ф.Н., Спиридонова Е.М. 2000. Уровень и образ жизни бомжей. Социс. Социологические исследования. № 2. С. 63-68.

Зубкова Е.Ю. 2013. «Бедные» и «чужие»: нормы и практики борьбы с нищенством в Советском Союзе. 1940-е - 1960-е годы. - Труды Института российской истории РАН. № 11. С. 285-310.

Карлинский И.3. 2004. Анализ социального и правового положения бездомных в современной России. СПб: Дельта. 64 с.

Коваленко Е., Строкова Е. 2010. Бездомность: есть ли выход? М.: Фонд «Институт экономики города». 128 с.

Крушанова Л.А. 2014. Закон «О тунеядцах» 1961 г. и его реализация на Дальнем Востоке. - Советский Дальний Восток в сталинскую и постсталинскую эпохи: сборник статей. Владивосток: ИИАЭ ДВО РАН. С. 122-128.

Левенстим А.А. 1900. Профессиональное нищенство, его причины и формы. Бытовые очерки. СПб: Тип. М.М. Стасюлевича. 161 с.

Максимов Е.Д. 1901. Происхождение нищенства и меры борьбы с ним. СПб: Тип. В. Киршбаума. 136 с. 
Осинский И.И., Хабаева И.М., Балдаева И.Б. 2003. Бездомные - социальное дно общества. - Социс. Социологические исследования. № 1. С. 53-58.

Пазио-Влазловская Д. 2015. Концепт «бездомные» на материале современной прессы. - Вестник Кемеровского государственного университета культуры и искусств. № 30. С. 147-154.

Ринн Е. 2008. Социальные и правовые аспекты проблемы бездомности в России (краткий обзор результатов исследования). - Бездомность в современной России: проблемы и пути их решения: Вестник межрегиональной сети «За преодоление социальной исключенности». Вып. 1. 144 с.

Римашевская Н.М. 2004. Бедность и маргинализация населения (социальное дно). - Социс. Социологические исследования. № 4. С. 33-44.

Слободкин Ю.М. 1980. Ответственность лиц, ведущих антиобщественный паразитический образ жизни. - Известия высших учебных заведений. Правоведение. № 3. С. 78-81.

Соловьева 3.Р. 2001. Реабилитация бездомных: Исследование «Ночлежки». Журнал социологии и социальной антропологии. № 03. С. 92-108.

Социальные и правовые и проблемы бездомности в России: По материалам межрегионального исследования. 2007. СПб. 72 с.

Сперанский С.В. 1897. К истории нищенства в России. СПб: Тип. В. Киршбаума. 46 с.

Стивенсон С.А. 1996. О феномене бездомности. - Социс. Социологические исследования. № 8. С. 26-33.

Халак О.Н. 2012. Юридические коллизии в правовом регулировании статуса бездомных после освобождения из мест лишения свободы: дис. ... к.ю.н. Владимир. $185 \mathrm{c}$.

Хвоин Н.Н. 2018. Становление и развитие системы государственной социальной помощи бездомным гражданам в современной России. - Право и образование. № 02. С. 137-150.

TALYNEV Valeriy Yegorovich, Dr.Sci. (Soc.), Associate Professor; Professor of the Chair of Social-humanitarian, Economic and Legal Disciplines, Voronezh Institute of the Ministry of Internal Affairs of the Russian Federation (5 Rublevskaya St, Ternovoe village, Semiluksky District, Voronezh Region, Russia, 396947; v.talynyov@yandex.ru) KHVOIN Nikolai Nikolaevich, Leading Specialist of the Department of Monitoring Wage Systems and Departmental Oversight, Committee on Labor and Employment of the Population of St. Petersburg (7 Galernaya St, St. Petersburg, Russia,190000;khv-nikolai@yandex.ru)

\section{ON THE QUESTION OF THE ESSENTIAL DEFINITION OF THE CONCEPT OF HOMELESS: THE HISTORICAL GENESIS}

\footnotetext{
Abstract. The article considers methodological approaches to the genesis of the concept of homeless, classifies approaches to its study, and clarifies the essence of the concept of homeless. On the base of sociological research in relation to the modern conditions of the development of statehood, the authors determine its content and propose the author's definition of the concept.
}

Keywords: homeless, beggars, vagrancy, shelter, social assistance 